\title{
Juniper dwarf mistletoe, Arceuthobium oxycedri (DC.) M. Bieb, in Balochistan Province, Pakistan
}

\author{
by William M. Ciesla ${ }^{1}$, Ghulam Mohammed ${ }^{2}$ and A. Hafeez Buzdar ${ }^{3}$
}

Arceuthobium oxycedri, occurs from central Spain, across southern Europe, North Africa, the Near East, the Himalayas and western China where it infects Juniperus species and other hosts of the family Cupressaceae. In Pakistan, A. oxycedri is presently known from a single location, the Ziarat Forest, an 88,000 ha forest of $J$. excelsa in northern Balochistan Province where it presently encompasses a more or less contiguous area of approximately $3,500 \mathrm{ha}$, or about $4 \%$ of the total forest area. A. oxycedri occurs over much of the upper headwaters of the Chasnak and the Sasnamana Valleys of the Ziarat Forest. In the infested portions of the Chasnak Valley, an estimated $31.76 \%$ of the host trees are infected with a mean area dwarf mistletoe rating (DMR) of 1.53 and an estimated $2.03 \%$ annual mortality rate. Nearly $50 \%$ of the infected trees have a DMR of 6 . By contrast, an estimated $22 \%$ of the trees in the Sasnamana Valley are infested with a mean area DMR of 0.52 . No recent tree mortality, directly attributable to $A$. oxycedri, was detected in the Sasnamana Valley and nearly $50 \%$ of the infected trees have a DMR of 1. A. oxycedri was also detected in portions of four adjoining drainages. It is estimated that these infestations have been present for at least 25 to 30 years. In two of the drainages, the host tree is widely scattered and there is only a limited potential for tree-to-tree spread. In the remaining two valleys, infestations occur in relatively well stocked forests and there is a high potential for tree-to-tree spread.

Key words: Arceuthobium oxycedri, dwarf mistletoe, Juniperus excelsa, Pakistan
Arceuthobium oxycedri se retrouve dans le centre de l'Espagne, dans tout le sud de l'Europe, le nord de l'Afrique, au Proche-Orient, dans les Himalayas et dans l'ouest de la Chine où il infecte les espèces Juniper et autres membres de la famille des Cupressacées. Au Pakistan, A. oxycedris a été retrouvé dans un seul endroit, la forêt de Ziarat, une forêt de 88000 ha de $J$. excelsa située dans le nord de la province de Balochistan où il affecte présentement une superficie plus ou moins contiguë de 3500 ha, soit environ $4 \%$ de la superficie forestière totale. $A$. oxycedri est présent dans la plupart des hauts versants des vallées de Chasnak et de Sasnamama de la forêt de Ziarat. Dans les zones infestées de la vallée de Chasnak, une proportion estimée à $31.76 \%$ des arbres hôtes est infectée selon un taux moyen de superficie du faux-gui (DMR) de 1.53 et on estime le taux de mortalité annuelle à $2.03 \%$. Près de $50 \%$ des arbres infectés ont un DMR de 6 . Par contre, une proportion estimée à $22 \%$ des arbres de la vallée de Sasnamana est infectée à un taux DMR de 0.52 . Aucune mortalité récente, directement attribuable à $A$ oxycedris a été détectée dans la vallée de Sasnamana alors que $50 \%$ des arbres infectés avait un taux DMR de 1 . A oxycedris a été également détecté dans quelques portions des bassins versants contigus. On estime que ces infestations sont sur place depuis au moins 25 à 30 ans. Sur deux bassins versants, l'arbre hôte est très dispersé et il n'y a qu'une faible possibilité de dispersion d'un arbre à l'autre. Dans les deux autres vallées, les infestations surviennent dans les forêts relativement bien stockées et il existe une forte possibilité de dispersion d'un arbre à l'autre.

Mots clés: Arceuthobium oxycedri, faux-gui, Juniperus excelsa, Pakistan

\section{Introduction}

Arceuthobium oxycedri (DC.) M. Bieb. has the most extensive natural range of all of the dwarf mistletoes. It occurs from central Spain east across the Mediterranean region of Europe and northern Africa, the Near East, the Himalayas and western China (Tibet) (Hawksworth and Wiens 1976). A. oxycedri infects several species of Juniperus which occur within its natural range and is also capable of infecting other plants of the family Cupressaceae which have been introduced into its

\footnotetext{
'Forest Protection Specialist, Forest Health Management International, 2248 Shawnee Court, Fort Collins, Colorado 80525, USA.

${ }^{2}$ Divisional Forest Officer, Ziarat District, Balochistan Forest Department, Ziarat, Pakistan.

${ }^{3}$ Sociologist, Enterprise and Development Consulting (EDC), Quetta, Pakistan.

${ }^{4}$ The Juniperus occurring in Balochistan is presently considered to be J. excel$s a$ based on the work of Stewart (1972). However, more recent literature (Rushforth 1987 , Vidakovic 1991) refers to J. excelsa as a species which occurs from the Balkan Peninsula east to the Caucasus Mountains with J. macropoda being the designation for the species which occurs in the mountainous regions of Afghanistan, Pakistan and India. The morphological differences between these two species is unclear, however, and to be consistent with current Pakistan convention, the designation $J$. excelsa is used in this paper.
}

range (e.g., Chamaecyparis thyoides, Cupressus arizonica, $C$. macrocarpa and Thuja orientalis (Hawksworth and Wiens 1996). In Pakistan, A. oxycedri is presently known from a single location, a forest of Juniperus excels $a^{4}$ near the community of Ziarat in northern Balochistan Province.

An assessment of $A$. oxycedri in the Ziarat Forest was made during the summer of 1997 as part of a Juniper Conservation and Management Sub-Project, a component of the Balochistan Natural Resources Management Project financed by The World Bank. Objectives of the assessment were to 1) identify areas infested by $A$. oxycedri, 2) estimate levels of intensity of infection and 3 ) recommend a program to reduce losses to the forest resource by this parasite.

\section{Background}

The Ziarat Forest consists of approximately 88,000 ha of Juniperus excelsa occurring between 1,980 and 3,350 m elevation and is considered to be the world's largest juniper forest. Climate is arid; precipitation averages approximately $323.8 \mathrm{~mm} /$ year. Soils are poorly developed with shallow profiles. Terrain is steep and rocky and approximately one third of the area consists of bare rock where soil is either absent or confined to a few crevasses (Sheikh 1985). 
$J$. excelsa occurs as pure or nearly pure, open, multi-storied stands. Associated woody plants include Fraxinus xanthoxyloides, occurring primarily along creek beds, Caragana ambigua, Artemisia maritima, Mentha sylvestris, Prunus eburnea, Berberis baluchistania and Cotoneaster basilaris. Increment is low, with $J$. excels $a$ averaging $25 \mathrm{~mm}$ in height growth and $1 \mathrm{~mm}$ of diameter growth annually. Tree form is generally poor, with many individuals having multiple stems, tapered and twisted trunks, poor crown form, extensive branch dieback and adventitious branches. Despite the harsh growing conditions, $J$. excelsa is long-lived and on the best sites can achieve large sizes ( $115 \mathrm{~cm}$ dbh and $15 \mathrm{~m}$ in height). Trees as old as 2,000 years have been documented. Much of the forest is in a degraded condition because local residents depend on the forest as a source of fuelwood and other forest products. The Forest is also heavily used as summer range for goats and sheep and is a key watershed and summer recreation area (Shiekh 1985).

The first report of $A$. oxycedri in the Ziarat Forest is by Beg (1973) who detected this parasite in the Sasnamana Valley, northeast of Ziarat, as part of a forest disease survey conducted by the Pakistan Forest Institute (PFI) in Peshawar. A second report (Jamal and Beg 1974) suggests that the parasite had been present in the area for some time but was overlooked because the aerial shoots mimic the foliage of its host plant. Discussions with local foresters of the Balochistan Forest Department (BFD) indicate that local people were aware of this plant at least as early as 1920 and routinely collected the aerial shoots for livestock feed. The practice of using $A$. oxycedri shoots as fodder is mentioned by Zakaullah and Badshah (1977) who expressed concern that this practice might spread the parasite. In 1977 , a survey by PFI detected $A$. oxycedri in the Chasnak Valley, immediately north of the Sasnamana Valley (Zakaullah 1977). An evaluation conducted in 1993 indicated that the area of heaviest infestation in the two valleys was the south side (north facing slope) of the Chasnak Valley (Ciesla 1993).

Dwarf mistletoe control was begun in 1978 in the Sasnamana Valley with the objective of eradicating the parasite. This project was funded for a five-year period, included cutting of heavily infected trees and pruning infected branches from less severely infected trees, and ended in 1983 because of lack of funds and concerns that tree cutting would have adverse effects on watershed and other forest values (Sheikh 1985).

\section{Methods}

\section{Known Areas of Infestation}

Surveys were conducted in the Chasnak and Sasnamana Valleys to establish the approximate perimeter of the infested area and intensity of infection. Sample plots, consisting of groups of 5 to 15 dominant or co-dominant junipers over an area of approximately $0.5 \mathrm{ha}$, were established throughout the two valleys. Each sample tree was examined for presence of dwarf mistletoe and infected trees were rated using the Hawksworth 6 class rating system (Hawksworth 1977) (DMR). Individual tree DMRs were averaged to obtain a plot DMR and an area DMR.

Informal examinations were made of trees en route to and between sample plots to detect presence of $A$. oxycedri. This allowed for classification of sample plots into three broad strata:

1. Some or all sample trees infected by dwarf mistletoe.

2. No sample trees infected but infected trees detected within close proximity to the sample point.
3. Sample trees free of infection and no infected trees within close proximity to the sample point.

A mean area DMR was calculated for the portion of each valley infested by $A$. oxycedri from the sample plots which either contained infected trees or where infected trees occurred within close proximity to the sample plot.

Other data elements collected at each sample plot included:

1. Plot location - determined by a combination of latitude/longitude readings taken with a Magellan global positioning system (GPS NAV 5000 DLX - Model 15005) and locating sample points on 1:50 000 scale topographic maps of the area.

2. Basal area, expressed in $\mathrm{ft}^{2} /$ acre, as determined by a BAF 10 wedge prism.

3. Diameter breast height (inches) of each sample tree recorded as "in" by the wedge prism.

4. Aspect and topographic position.

Informal observations were also made on overall forest condition.

Tree decline and mortality due to dwarf mistletoe is a slow process which takes place over a period of years. An attempt was made to estimate an annual rate of tree mortality attributable to $A$. oxycedri by identifying those trees occurring in the sample plots which were in a "terminal state of decline." These were defined as trees with extensive crown dieback, evidence of profuse witches brooms throughout both the live and dead portions of the crown and the presence of dwarf mistletoe aerial shoots which were chlorotic because the host tree no longer had sufficient vigor to support them. These trees were predicted to die within the 1997 or 1998 growing seasons.

\section{Detection of New Infestations}

Detection of $A$. oxycedri beyond the Chasnak and Sasnamana Valleys was done via informal reconnaissance surveys. Unconfirmed reports of possible infested areas and the knowledge of local forest guards and other forest workers was used to determine which areas to examine. Moreover, forest guards advised local herders, farmers and other individuals who make frequent visits to the forest that they were interested in receiving information on the occurrence of $A$. oxycedri. Since livestock find the aerial shoots of $A$. oxycedri to be a palatable and nutritious forage, many of the area's residents are familiar with the plant. Areas from which reports of possible infections were received were examined.

\section{Results and Discussion \\ Forest Condition}

The forest throughout the Chasnak Valley consists of scattered patches of $J$. excelsa woodland on the mountain slopes while the level areas associated with the major streams and some of the larger tributaries are free of trees. These breaks serve as natural barriers to tree-to-tree spread of dwarf mistletoe. As the terrain becomes steeper and rockier, the junipers become more scattered. The areas with the best stocking are located on benches on the north-facing sides of the Chasnak Aghbarai and Chasnak Aghbarg, two of the three major streams in this valley. Basal area averages less than $20 \mathrm{ft}^{2} /$ acre $\left(4.61 \mathrm{~m}^{2} / \mathrm{ha}\right)$.

The juniper forest in the Chasnak Valley is in generally poor condition. This is partially due to the harsh, arid environment and heavy use by local residents. Excessive harvesting of juniper for fuelwood and overgrazing has left most of the accessible 


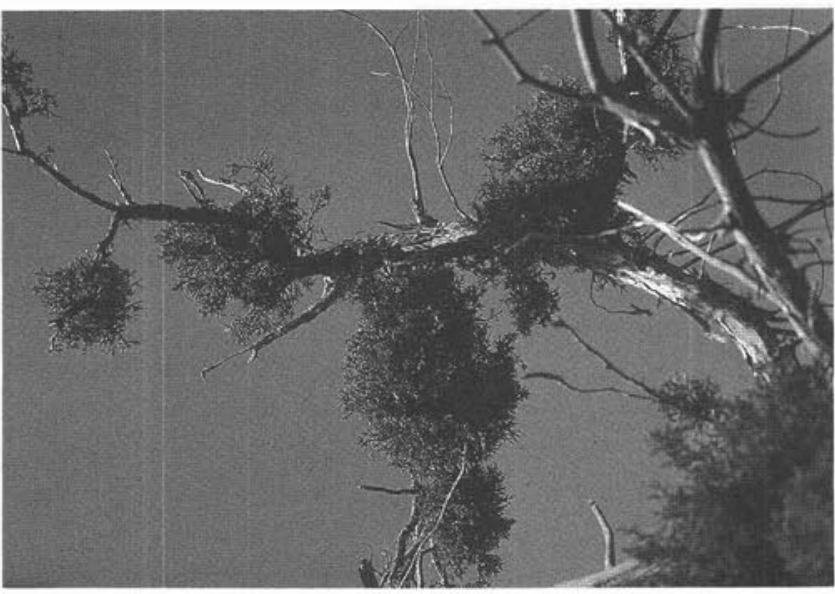

Fig. 1. Large, globose plants of Arceuthobium oxycedri on Juniperus excelsa, Chasnak Valley, Balochistan Province, Pakistan.

areas in a severely degraded condition. Cutting of live trees has been illegal for several years and it is a common practice for herdsmen and local villagers to girdle one or more stems of multi-stemmed junipers. When the girdled stems die, they are harvested for fuelwood.

The lower slopes of the southwest aspect of the Sasnamana Valley are relatively gentle and contain a juniper forest with substantially higher stocking levels than those encountered in the Chasnak Valley. Basal areas range between $60-80 \mathrm{ft}^{2} /$ acre $\left(13.83-18.44 \mathrm{~m}^{2} / \mathrm{ha}\right)$. The northeast-facing slope, on the other hand, is steep, rocky and consists of widely scattered junipers except in a few relatively level areas where stocking is somewhat heavier. This valley is more heavily populated than the Chasnak Valley with permanent human settlements and orchards extending about half the length of the valley bottom. There is also a scattering of tent camps of nomadic herders throughout the forest.

Despite the heavier human population, the juniper forest in the Sasnamana Valley appears to be less severely degraded than the Chasnak Valley. This may be the result of higher levels of stocking and somewhat better growing conditions.

\section{Detection of Infected Trees}

Dieback and adventitious branching on junipers throughout the Ziarat Forest, attributed to harsh growing conditions, old age and periodic drought, mimics symptoms commonly associated with dwarf mistletoe infection (dieback and witches brooms). Witches brooms caused by $A$. oxycedri are nonsystemic, localized and relatively small, and do not appear until infected trees are weakened to the point that there is visible crown thinning.

The aerial shoots of $A$. oxycedri mimic juniper foliage. Generally there is a slight color difference between the juniper foliage and the aerial shoots of $A$. oxycedri, with the latter being an olive-green color in contrast to the green or blue-green foliage of the juniper. This is especially true of the staminate plants which have flower buds that are a distinct yellow-green color. Some pistillate plants are virtually the same color as the juniper foliage, however, and even large plants are difficult to detect from a short distance if they are growing amid juniper foliage. Older dwarf mistletoe plants are large, distinctly globose in shape and relatively conspicuous when growing on portions of branches devoid of host foliage (Figure 1). Young plants (less than five years old) are inconspicuous and virtually impossible to detect.
Table 1. Comparison of $A$. oxycedri infection on Juniperus excelsa, Chasnak and Sasnamana Valleys, Ziarat Forest, Balochistan Province, Pakistan, July 1997

\begin{tabular}{lcccc}
\hline Area & $\begin{array}{c}\text { Plots } \\
\text { Established }\end{array}$ & $\begin{array}{c}\text { Plots in } \\
\text { Infested Area }\end{array}$ & \% Infection & $\begin{array}{c}\text { Mean } \\
\text { DMR }\end{array}$ \\
\hline Chasnak & 25 & 15 & 31.76 & 1.53 \\
Sasnamana & 17 & 9 & 22.00 & 0.52 \\
\hline
\end{tabular}

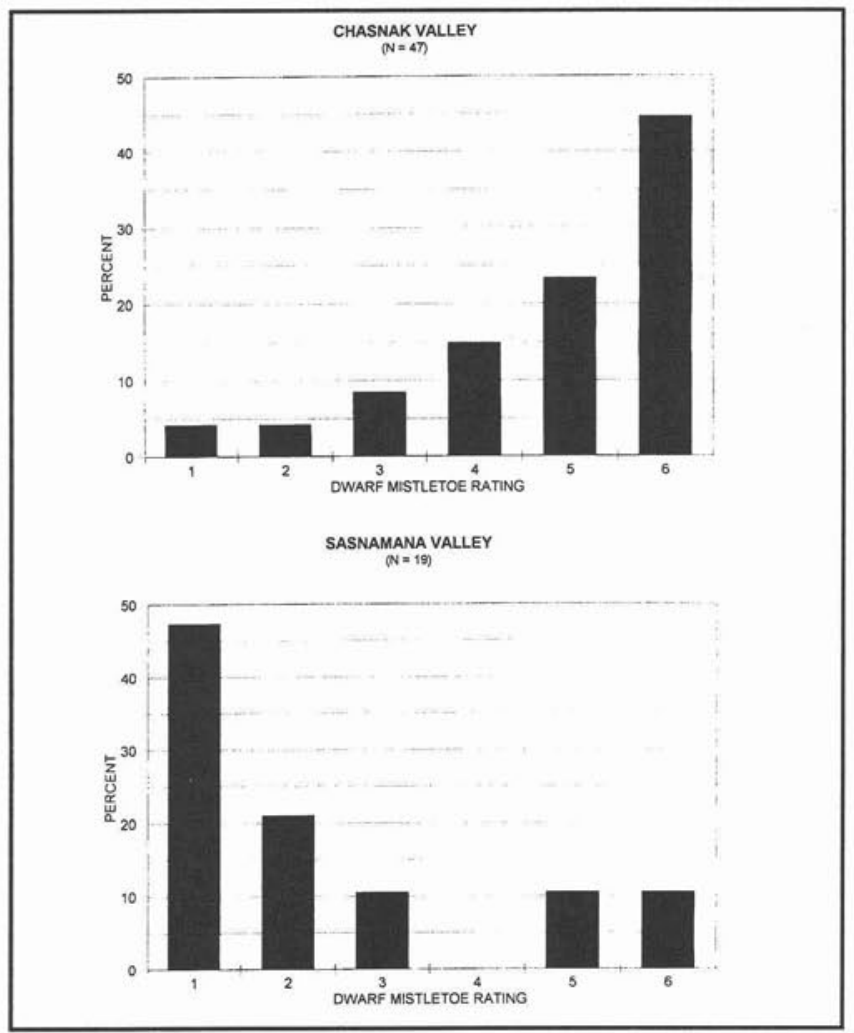

Fig. 2. Frequency distribution of dwarf mistletoe infected trees by DMR, Chasnak and Sasnamana Valleys, Balochistan Province, Pakistan, July 1997.

\section{Chasnak and Sasnamana Valleys}

Of a total of 25 sample plots, containing 238 sample trees, established in the Chasnak Valley, 15 plots, containing 148 trees, either had dwarf mistletoe-infected trees within the sample plots or in close proximity to the sample plot. Proportion of infected trees was $31.76 \%$ with an area DMR of 1.53 (Table 1). Nearly one half of the infected trees occurring in the plots had a DMR rating of 6 (Figure 2).

Dwarf mistletoe infestations were detected in the upper portions of both the Chasnak Aghbargai and Chasnak Aghbarg forks of the Chasnak Valley (Figure 3). Infested areas are typically spotty and are often interspersed with areas where $A$. oxycedri is absent. In many instances individual trees may be heavily infected (DMR $=4-6$ ) while adjacent trees are free of infection. There is a scattering of dead trees, presumably the result of dwarf mistletoe, throughout the infested area. These trees appear to have died over a long period of time.

No infected trees were found in the Chasnak Surai drainage (Figure 3). This area was examined thoroughly because the report by Zakaullah (1977) includes a map which shows $A$. oxycedri in several locations in this drainage as well as in the watershed immediately to the east. This map apparently is in error. 


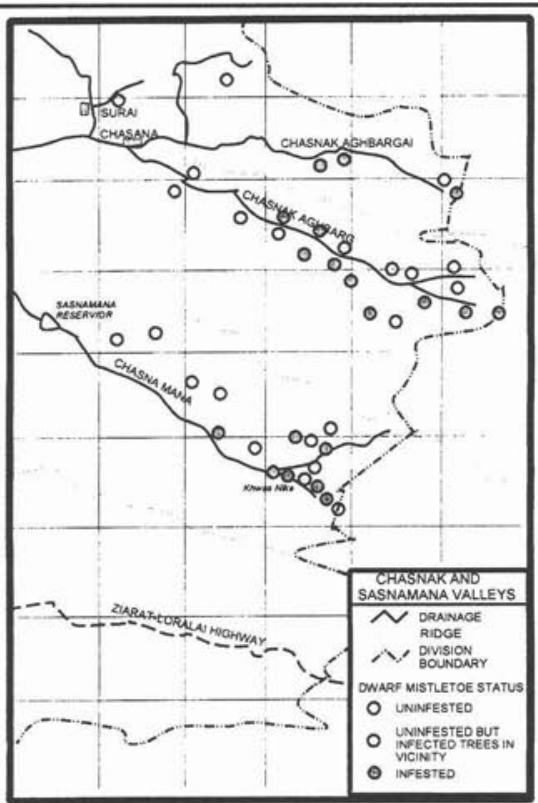

Fig. 3. Distribution of sample plots and dwarf mistletoe incidence, Chasnak and Sasnamana Valleys, Balochistan Province, Pakistan July 1997 (Each grid represents 15 minutes of latitude and longitude).

Seventeen plots, containing 166 trees, were established in the Sasnamana Valley. Of these, nine plots with 86 trees, either contained infected trees or had infected trees in close proximity. Twenty two percent of the trees in plots occurring in infested areas were infected with a mean DMR of 0.52 (Table 1). The infested area in the Sasnamana Valley appears to be centered in the vicinity of a spring known as Khwas Nika (Figure 3). There is extensive old tree mortality in this area which apparently led to the original discovery of $A$. oxycedri. The dead trees are concentrated in a relatively small area. This is not typical of the pattern of tree mortality normally associated with this parasite, which tends to be a scattering of dead trees. On the other hand, in an arid climate, rate of decay of dead trees by fungi and other agents is slow and dead trees tend to remain standing for extended periods ( 30 to 50 years).

There is a striking difference in the intensity of dwarf mistletoe infection between the Chasnak and Sasnamana Valleys, with infection being much more severe in the Chasnak Valley. This is partially reflected in the percent infection and area DMR ratings for the two valleys (Table 1). In the Chasnak Valley, nearly one half of the infected trees have a DMR of 6.0 and there is a high incidence of infected trees in DMR classes 4 and 5. Just the opposite is true in the Sasnamana Valley where nearly half of the infected trees are in DMR class 1 and correspondingly lower proportions of trees occur in the more severe DMR classes (Figure 2). Differences in infection intensity could be due to stand condition. The more open forests of the Chasnak Valley may limit tree-to-tree spread of the dwarf mistletoe. Consequently, when a tree becomes infected, those dispersing dwarf mistletoe seeds which happen to land on a "safe site" and can germinate, land on the same tree. This can result in extremely heavy infections on individual trees with little or no infection of neighboring trees. Another possible explanation for the difference in intensity of infection is the fact that dwarf mistletoe control was conducted in the Sasnamana Valley between 1978 and 1983 (Sheikh 1985).

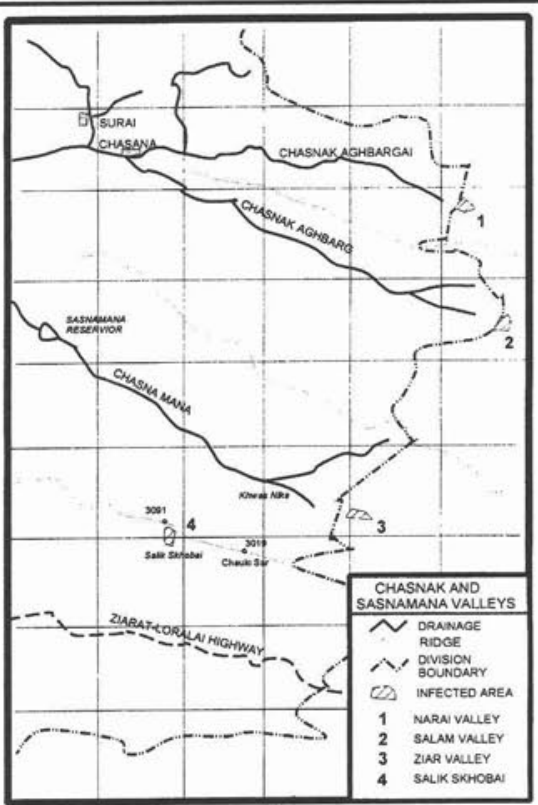

Fig. 4. Location of $A$. oxycedri infestations outside of the Chasnak and Sasnamana Valleys, Balochistan Province, Pakistan, July 1997 (Each grid represents 15 minutes of latitude and longitude).

The number of dead and dying trees classified as being in a state of terminal decline which could be attributed to dwarf mistletoe infection is low. All trees classified in this condition $(\Sigma=3)$ occur in the Chasnak Valley. Assuming that all of the trees classified as in a state of terminal decline would die during a single growing season, this would indicate an annual mortality rate of $2.03 \%$ in the Chasnak Valley. While this may appear to be a relatively low rate, when projected over time it represents a loss of approximately $50 \%$ of the forest over a period of 35 years, assuming that mortality is constant and there is no replacement due to natural regeneration.

There was no discernable pattern of infestation relative to slope, aspect or topographic position.

\section{Other Areas of Infestation}

In addition to the Chasnak and Sasnamana Valleys, $A$. oxycedri was detected in four sites; the upper headwaters of the Narai, Salam and Ziãr Valleys and in a location known as Salik Skhobai on the dividing ridge between the Sasnamana and Ziarat Valleys (Figure 4).

The Narai Valley lies immediately to the east of the Chasnak Aghbargai fork of the Chasnak Valley. Infected trees continue to occur in small groups on the Chasnak/Narai divide and into the Narai Valley (Figure 4 - location 1), first as multiple tree groups and further downslope as scattered single trees with heavy infections (DMR 5-6). Further east, the juniper trees become scattered and there is little potential for tree-to-tree spread because of the wide spacing between trees.

The Salam Valley is east of the Chasnak Aghbarg fork of the Chasnak Valley. There is a continuation of A. oxycedri infestation from the Chasnak Valley across the divide onto the Salam Valley (Figure 4 - location 2). The head of this valley is steep and rocky, however, and beyond the immediate area of the divide, where the terrain is fairly level, there is little or no juniper until the valley bottom where juniper woodland occurs on a few areas of fairly level terrain. The potential for spread 
of $A$. oxycedri in this area is limited by the lack of host material of suitable stand density.

The Ziãr Valley lies immediately east of the Sasnamana Valley. Following an earlier evaluation of this parasite (Ciesla 1993) the Divisional Forest Officer, Ziarat Division, BFD, visited the upper portions of this valley and detected what he believed to be dwarf mistletoe-infected junipers. A general reconnaissance of this area confirmed the presence of at least four separate areas of infestation. Two of the areas contain groups of 10 to 12 infected trees and two are single, heavily infected trees $(\mathrm{DMR}=6)$. One of the areas of multiple tree infestation had a DMR of 1.22 and contained one tree in a state of terminal decline. The eastern-most location consisted of a single DMR class 6 tree (Figure 4 - location 3). The Ziãr Valley contains a relatively well stocked juniper forest. Because of the continuous area of forest in this valley, there is a high potential for tree to tree spread of dwarf mistletoe.

Possible occurrence of dwarf mistletoe infestation in an area known as Salik Skhobai, located on the south face of the ridge which divides the Sasnamana and Ziarat Valleys, was reported to a Forest Guard. Examination of this area confirmed the presence of a dwarf mistletoe infection with several trees in DMR class 6 (Figure 4 - location 4). Two separate groups of infected trees were found. The individual who reported this infestation indicated that he had been aware of its occurrence for at least eight years. The juniper forest in this area is relatively well stocked and the infestation poses a high potential for tree to tree spread.

All areas of $A$. oxycedri infestation detected beyond the Chasnak and Sasnamana Valleys are well developed and contain large, robust dwarf mistletoe plants. It is estimated that these areas have been infected for at least 25 to 30 years. All appear to be extensions of the main area of infestation in the Chasnak and Sasnamana Valleys (Figure 4).

The known $A$. oxycedri infection in the Ziarat Forest comprises a gross area of approximately 3,500 ha or $4 \%$ of the juniper forest. The infested area lies more or less perpendicular to the general terrain which includes three east-west ridges, each of which contain peaks in excess of 3,000 meters (Figure 4). The more or less contiguous character of the infestation suggests that spread is primarily tree-to-tree via direct seed dispersal. The role of birds and small mammals in the overland dispersal of seeds is not known. Zakaullah and Badshah (1977) report observing a bird which they refer to as a "mistle thrush," to be common during the period of $A$. oxycedri seed dispersal and suggest that birds and field rats could serve as vectors for the overland spread of this parasite.

\section{Conclusions}

The Ziarat Forest consists of approximately 88,000 ha of nearly pure, open-grown stands of Juniperus excelsa. Much of this forest is in a degraded condition due to excessive levels of fuelwood harvesting and overgrazing. Occurrence of dwarf mistletoe, $A$. oxycedri, on J. excelsa in portions of the Ziarat Forest has been known since 1973.

$A$. oxycedri occurs over much of the upper headwaters of the Chasnak and the Sasnamana Valleys of the Ziarat Forest. In the infested portions of the Chasnak Valley, an estimated $31.76 \%$ of the host trees are infected with a mean area DMR of 1.53 and an estimated $2.03 \%$ annual mortality rate. Nearly $50 \%$ of the infected trees have a DMR of 6 . By contrast, an estimated $22 \%$ of the trees in the Sasnamana Valley are infested with a mean area DMR of 0.52 . No recent tree mortality, directly attributable to $A$. oxycedri, was detected in the Sasnamana Valley and nearly $50 \%$ of the infected trees have a DMR of 1. Differences in the levels and severity of infestation between the two valleys is attributed to differences in stand condition and the fact that dwarf mistletoe control was carried out in the Sasnamana Valley during the years 1978 to 1983.

A. oxycedri was also detected in portions of four adjoining drainages. These areas are localized but contain well developed dwarf mistletoe plants and severely infected trees. It is estimated that these infestations have been present for at least 25 to 30 years. In two of the drainages, the host tree is widely scattered and there is only a limited potential for treeto-tree spread. In the remaining two valleys, infestations occur in relatively well stocked forests and there is a high potential for tree-to-tree spread. The potential for overland spread of dwarf mistletoe seeds by birds and small mammals is not known.

The $A$. oxycedri infestation in the Ziarat forest presently encompasses a more or less contiguous area of approximately 3,500 ha, representing about $4 \%$ of the total area of juniper cover in the area.

\section{Acknowledgments}

The work described in this paper was done under the Balochistan Natural Resources Management Project financed by The World Bank and managed by a consortium of private consulting companies including EDC and Environmental Resources Management (ERM), UK.

\section{References}

Beg, A. R. 1973. Survey of diseases of conifers and selected hardwoods. Pakistan Forest Institute, Peshawar, PL480 Project A17F.SS15. Annual Technical Report 1, August 1972-31 July 1973. 7 p.

Ciesla, W.M. 1993. Assessment of dwarf mistletoe and other factors affecting the health of forests in Balochistan. FAO, Rome, Italy, PAK/88/071. 24 p.

Hawksworth, F.G. 1977. The 6-class dwarf mistletoe rating system. USDA Forest Service, Rocky Mountain Forest and Range Experiment Station. General Technical Report RM-48. Fort Collins, Colorado. 7 p.

Hawksworth, F.G. and D. Wiens. 1976. Arceuthobium oxycedri and its segregates $A$. juniperi-procerae and $A$. azoricum (Viscaceae). Kew Bulletin 31: 71-80.

Hawksworth, F.G. and D. Wiens. 1996. Dwarf mistletoes: biology, pathology and systematics, USDA Forest Service, Agri. Handbook 709. $410 \mathrm{p}$.

Jamal, S. M. and A.R. Beg. 1974. Natural infection of mistletoes in Pakistan. In Proceedings Pakistan Forestry Conference (Nov. 48, 1974). pp. 187-189.

Rushforth, K.D. 1987. Conifers. New York and Oxford: Facts on File Publications. 232 p.

Sheikh, M.I. 1985. Afforestation in juniper forests of Balochistan. Pakistan Forest Institute, Peshawar. 46 p.

Stewart, R.R. 1972. An annotated catalogue of the vascular plants of West Pakistan and Kashmir. Fakhri Printing Press, Karachi.

Vidakovic, M. 1991. Conifers - Morphology and variation. CABI Wallingford, Oxon, UK. 754 p.

Zakaullah. 1977. Survey of juniper dwarf mistletoe in the adjacent areas of Sasnamana State Forest of Balochistan. Pakistan Journal of Forestry 26: 143-146.

Zakaullah and K. Badshah 1977. Survey of juniper dwarf mistletoe in Sasnamana State Forest of Balochistan. Pakistan Journal of Forestry 27: $39-50$. 